\title{
BMJ Open Neighbourhood characteristics and mental disorders in three Chinese cities: multilevel models from the World Mental Health Surveys
}

\author{
Alexandre Dias Porto Chiavegatto Filho, ${ }^{1}$ Laura Sampson, ${ }^{2}$ Silvia S Martins, ${ }^{3}$ \\ Shui Yu, ${ }^{2}$ Yueqin Huang, ${ }^{4}$ Yanling He,${ }^{5}$ Sing Lee, ${ }^{6}$ Chiyi Hu, ${ }^{7}$ Alan Zaslavsky, \\ Ronald C Kessler, ${ }^{8}$ Sandro Galea ${ }^{2,3}$
}

To cite: Chiavegatto Filho ADP Sampson L, Martins SS, et al. Neighbourhood characteristics and mental disorders in three Chinese cities: multilevel models from the World Mental Health Surveys. BMJ Open 2017;7:e017679. doi:10.1136/ bmjopen-2017-017679

- Prepublication history for this paper is available online. To view these files, please visit the journal online (http://dx.doi org/10.1136/bmjopen-2017017679).

Received 9 May 2017 Revised 17 August 2017 Accepted 20 September 2017

CrossMark

For numbered affiliations see end of article.

Correspondence to

Dr Sandro Galea;

sgalea@bu.edu

\section{ABSTRACT}

Objectives The rapid growth of urban areas in China in the past few decades has introduced profound changes in family structure and income distribution that could plausibly affect mental health. Although multilevel studies of the influence of area-level socioeconomic factors on mental health have become more common in other parts of the world, a study of this sort has not been carried out in Chinese cities. Our objectives were to examine the associations of two key neighbourhood-level variables-median income and percentage of married individuals living in the neighbourhood - with mental disorders net of individual-level income and marital status in three Chinese cities.

Setting Household interviews in Beijing, Shanghai and Shenzhen, PRC, as part of the cross-sectional World Mental Health Surveys.

Participants 4072 men and women aged 18-88 years. Primary and secondary outcome measures Lifetime and past-year internalising and externalising mental disorders.

Results Each one-point increase in neighbourhoodlevel percentage of married residents was associated with a $1 \%$ lower odds of lifetime $(p=0.024)$ and $2 \%$ lower odds of past-year $(p=0.008)$ individual-level externalising disorder, net of individual-level marital status. When split into tertiles, individuals living in neighbourhoods in the top tertile of percentage of married residents had $54 \%$ lower odds of a pastyear externalising disorder $(\mathrm{OR}=0.46,95 \% \mathrm{Cl}$ : 0.24 to 0.87 ) compared with those in the bottom tertile. Neighbourhood-level marital status was not statistically associated with either lifetime or pastyear internalising disorders. Neighbourhood-level income was not statistically associated with odds of either internalising or externalising disorders.

Conclusions The proportion of married residents in respondents' neighbourhoods was significantly inversely associated with having externalising mental disorders in this sample of Chinese cities. Possible mechanisms for this finding are discussed and related to social causation, social selection and social control theories. Future work should examine these relationships longitudinally.
Strengths and limitations of this study

- We are the first to our knowledge to investigate the association of neighbourhood characteristics with mental disorders in large urban areas of China.

-We completed various sensitivity analyses including different types of regression models in order to account for both the complex survey design and the multilevel nature of the our data, as well as different ways of operationalising the exposure variables, and found that our results were robust across different methods and models.

- We applied statistical weights to our analyses in order to ensure that our sample was representative of the demographics in the included cities.

- The cross-sectional design does not allow us to examine temporality of our exposures and outcomes.

- The data were collected from 2002 to 2007; these cities are likely to have changed demographically in the decade since data collection and therefore our results may not be as generalisable to today's population.

\section{INTRODUCTION}

China, the world's most populous country, has recently experienced one of the largest internal migration processes in human history; the proportion of the population living in urban areas increased from about $36 \%$ in 2000 to $50 \%$ in $2011 .{ }^{12}$ Mental disorders are an important concern in urban areas with rapid and unequal growth. ${ }^{3}$ Despite important early gains in personal well-being, recent studies have suggested that the negative effects of rapid urbanisation on the mental health of Chinese residents may have now caught up with the potential benefits of economic growth. ${ }^{45}$ Results from the Global Burden of Disease Study found that mental disorders accounted for seven of the top 20 causes of years living with a disability in China, with all disorders increasing in absolute terms 
from 1990 to $2010 .{ }^{4}$ It is estimated that around 173 million Chinese adults have a mental disorder, 158 million of who have never received any professional treatment. ${ }^{6}$

Based on this literature, it is becoming increasingly important to characterise the risk and protective factors for mental disorders in urban China. Individual factors such as demographics and socioeconomic position have long been known to be associated with mental disorders in urban areas worldwide, but neighbourhood characteristics are a growing area of concern, especially in rapidly developing countries. ${ }^{78}$ Neighbourhoods are responsible for the conditions in which people are born, grow, live and age; neighbourhood-level characteristics may represent both an important driver of mental health and an opportunity for prevention. ${ }^{9}$

Extant work has shown that neighbourhood characteristics such as economic disadvantage, social interactions and income inequality are associated with depression and other mental disorders in urban areas. ${ }^{10-12}$

While research has examined the association between neighbourhood factors and physical health in Shanghai, ${ }^{13}$ no previous analyses to our knowledge have assessed associations of neighbourhood-level factors with mental health in Chinese cities. Furthermore, we expect there to be differences in the neighbourhood-level explanatory factors for different types of mental disorders, as there are at the individual level in this population. ${ }^{14}$ As a way of categorising different outcomes, internalising disorders are defined as those whose symptoms are typically expressed inwardly, such as anxiety and depression, whereas externalising disorders are those that present outwardly with behaviour, such as intermittent explosive disorder or alcohol abuse. ${ }^{15}$

The association of internalising and internalising disorders with neighbourhood factors has been previously described in other contexts. A study of African American adolescents in the USA, for example, found that higher neighbourhood poverty and unemployment levels predicted the presence of internalising symptoms via lower social support. ${ }^{16}$ On the other hand, a study of Mexican American youth found that while the interaction of neighbourhood disadvantage with child generation predicted the presence of stressful life events, neighbourhood disadvantage as a main effect was not associated with internalising or externalising symptoms. ${ }^{17}$ However, this type of study has not been conducted, to our knowledge, in the adult population of urban China.

To better understand the potential role of neighbourhood factors in determining mental health in this context, we analysed epidemiological survey data collected in three of the largest urban areas in China: Beijing, Shanghai and Shenzhen. We focused on two neighbourhood-level contextual variables that we hypothesised to be associated with prevalence of mental disorders: neighbourhood-level income and percentage of neighbourhood residents who are married.

The focus on income is based on abundant evidence that group-level income is associated with health indicators in other countries, even when taking into account individual income. ${ }^{18}{ }^{19}$ Neighbourhood-level income could be associated with availability of salutary resources that would otherwise not be present in particular neighbourhoods. ${ }^{20}$ Furthermore, neighbourhood-level income may be associated with strong prosocial forces such as social cohesion that are themselves linked to better health. ${ }^{22} 23$

The focus on marriage was motivated by a previous study in China which found that being unmarried was associated with higher odds of having a mood disorder as well as with the severity of such disorders, ${ }^{14}$ possibly a manifestation of the importance of family-oriented life in Chinese culture. In addition, reports of the importance of family arrangements in overall community life in China, such as in social interactions and political participation, ${ }^{24}$ suggest that neighbourhood-level family relations could plausibly have an effect on mental disorders after accounting for individual marital and relationship status.

\section{METHODS}

\section{Sample}

Our sample was composed of residents aged 18-88 years in the cities of Beijing, Shanghai and Shenzhen who participated in the World Mental Health (WMH) Survey Initiative (table 1). The Beijing and Shanghai surveys were carried out in 2002-2003 and the Shenzhen survey in 2006-2007. The samples in all three cities were based on a multistage area clustered household survey design, described in detail elsewhere. ${ }^{142526}$

Neighbourhoods in this sample consisted of neighbourhood committees (NCs), the official, local community organisations in urban China that consist of 100-700 households, and that were also used as the primary sampling unit in the WMH study in China. ${ }^{14}$ These neighbourhoods represent the areas of China in which respondents currently lived at the time of the survey. In Shenzhen, work units (eg, schools or companies) were also used as primary sampling units in addition to NCs, in order to capture temporary residents living in the city for at least 1 year. After combining Beijing, Shanghai and Shenzhen and including both NCs and work units under the definition of neighbourhood for this study, our sample consisted of 143 total neighbourhoods.

All participants completed part I of the survey, which assessed core disorders and demographics, while a probability subsample consisting of all respondents who met lifetime criteria for any part I disorder plus a probability subsample of $25 \%$ of other part I respondents completed part II ( $\mathrm{n}=914$ in Beijing; $\mathrm{n}=714$ in Shanghai; and $\mathrm{n}=2476$ in Shenzhen; table 1). The sample was weighted to adjust for differential sampling of part I respondents into part II; for differential probability of selection within households (one respondent selected for interview in each household regardless of household size, creating an inverse association between number of household residents and probability of selection); and to match sociodemographic 
Table 1 WMH sample characteristics by city

\begin{tabular}{|c|c|c|c|c|c|c|c|}
\hline \multirow[t]{2}{*}{ City } & \multirow[t]{2}{*}{ Survey* } & \multirow[t]{2}{*}{ Sample characteristics } & \multirow[t]{2}{*}{ Field dates } & \multirow[t]{2}{*}{ Age range } & \multicolumn{2}{|c|}{ Sample size } & \multirow[t]{2}{*}{$\begin{array}{l}\text { Response } \\
\text { rate† }\end{array}$} \\
\hline & & & & & Part I & Part II & \\
\hline Shenzhen & Shenzhen & $\begin{array}{l}\text { Shenzhen metropolitan area; } \\
\text { included temporary residents } \\
\text { as well as household residents }\end{array}$ & 2006-2007 & $18-88$ & 7134 & 2476 & 80.0 \\
\hline
\end{tabular}

${ }^{*} B-W M H$ (The Beijing World Mental Health Survey); S-WMH (The Shanghai World Mental Health Survey).

†The response rate is calculated as the ratio of the number of households in which an interview was completed to the number of households originally sampled, excluding from the denominator households known not to be eligible either because of being vacant at the time of initial contact or because the residents were unable to speak the designated languages of the survey. The weighted average response rate is $77.7 \%$.

distributions in the respective cities. ${ }^{26}$ The weighted part II sample represents the distribution of mental disorders and marital status in the entire sample without bias, and adjusts the sample for minor discrepancies from the population on the distributions of age, sex and marital status.

The analyses reported in this paper are based on the weighted part II sample, with the exception of 32 respondents $(0.2 \%$ of the weighted part II sample) who refused to answer or answered 'do not know' on a key covariate, resulting in a final analytic sample of 4072 respondents.

\section{Data collection}

WMH interviews were administered face to face in the homes of respondents by trained lay interviewers. The WMH interview schedule was translated using a standardised World Health Organization (WHO) translation, back translation and harmonisation protocol. ${ }^{27}$ Written, informed consent after a full description of the study was obtained from all participants before conducting the surveys. These consent procedures were approved by the ethics committees of Peking University and Shenzhen Kangning Hospital.

\section{Measures}

Primary outcome: mental disorders

Mental disorders were assessed with the WHO Composite International Diagnostic Interview (CIDI) V.3.0. ${ }^{28}$ The disorders assessed included internalising disorders (post-traumatic stress disorder, panic disorder, specific phobia, social phobia, agoraphobia, adult separation anxiety, generalised anxiety disorder, major depressive disorder, dysthymic disorder and bipolar/subthreshold bipolar disorders) and externalising disorders (intermittent explosive disorder and alcohol and drug abuse with or without dependence). Diagnoses were based on the definitions and criteria of the American Psychiatric Association's Diagnostic and Statistical Manual of Mental Disorders, Fourth Edition (DSM IV). ${ }^{29}$ Both lifetime and past-year diagnoses were assessed. Clinical calibration studies carried out in a number of WMH countries confirmed good concordance of DSM-IV diagnoses based on the CIDI with diagnoses based on blinded clinical reappraisal interviews using the Structured Clinical Interview for DSM-IV. ${ }^{30} 31$

\section{Individual-level fixed effects}

Individual-level covariates chosen for this analysis included age (categorised into 35-49, 50-64 and 65+ vs 18-34), sex (female vs not), marital status (currently married vs not), employment status (currently unemployed vs not unemployed vs 'do not know' or refused to answer), migrant status (migrant to the current city vs not, where migrant was defined as not 'raised mostly in a large city'), income and education. For income, individual per-capita income was first calculated as the combined income of all family members divided by the number of family members. The ratio of each respondent's individual per-capita income to the median city-level income was then calculated using each city's full sample (including both parts I and II). Finally, this variable was centred so that the mean was equal to 0 , and used as the continuous individual income exposure variable. Individual education was categorised as being above versus below the median of country-level education.

\section{Neighbourhood-level fixed effects}

We divided the median income in each neighbourhood (using each city's full sample, both parts I and II) by the city-level median to calculate relative neighbourhood-level income. The neighbourhood-level marital status variable was calculated as the weighted proportion of married individuals in each neighbourhood, again using the full sample in all cities. Both of these continuous variables were then centred so that the means were equal to 0 , and used as the main neighbourhood-level fixed effects. Each of these variables was also split into tertiles to classify each neighbourhood as high, intermediate or low on these measures and used as categorical fixed effects for an additional sensitivity analysis. 


\section{Data analysis}

Data analyses were carried out using SAS V.9.4. We used SAS survey procedures to calculate valid design-based standard errors for frequencies and means. Regression models were first run with a random intercept varying at the neighbourhood level as the only independent variable in order to calculate the intraclass correlation coefficient, which estimates the proportion of variation in the disorder outcomes that can be attributed to the neighbourhood. ${ }^{32}$

Weighted, multilevel, multivariate logistic regression models were then run using Proc Glimmix with neighbourhood as the repeated subject and both lifetime and past-year internalising and externalising disorders as the outcomes. Zero $\mathrm{G}$ tests were run in order to test for the random effect of the intercept in each model. ${ }^{32}$

As a sensitivity analysis, we also ran multilevel models using a jackknife resampling method for estimation of variance and SAS Surveylogistic regressions, and found very similar results across all three methods, suggesting robust findings (tables available on request).

\section{RESULTS}

\section{Prevalence of mental disorders (outcome)}

Ten per cent of the weighted analytic sample met criteria for lifetime history of any internalising disorder, while $4.7 \%$ met criteria for lifetime history of any externalising disorder (table 2). Six per cent had past-year internalising disorder, and $2.7 \%$ had past-year externalising disorder.

\section{Distributions of independent variables}

About half $(49.3 \%)$ of respondents were female; the majority was younger than 35 years old $(62.0 \%) ; 59.0 \%$ were married; $63.9 \%$ were migrants to a large city; and $3.2 \%$ were unemployed. The mean ratio of individual income to median city income was 1.63 .

The mean ratio of neighbourhood median income to city median income was 1.05 . The mean percentage of married individuals in each neighbourhood was $61.7 \%$.

\section{Random-intercept-only models}

The intraclass correlation coefficients for variation at the neighbourhood level were calculated from random-intercept-only models (not shown in tables) to be 0.04 and 0.16 for any lifetime internalising and externalising disorder respectively, and 0.07 and 0.09 for any past-year internalising and externalising disorder, respectively. In other words, neighbourhoods explained the greatest proportion of variation of the outcome $(16 \%)$ in the model for history of lifetime externalising disorder.

\section{Lifetime mental disorder models}

Table 3 reports multivariate logistic regressions with individual-level variables only (first column), neighbourhood-level income as the main independent variable of interest (second column) and neighbourhood-level percentage of married individuals as the main independent variable of interest (third column) with any lifetime internalising disorder as the outcome. The associations between the individual-level variables and this outcome were modest; the only statistically significant association was found was between higher individual income (OR 1.05, 95\% CI 1.02 to 1.09 for all three models) and lifetime internalising disorder.

Neither neighbourhood-level income nor neighbourhood-level marital status was statistically significantly associated with lifetime internalising disorder. Additionally, the random effect of the intercept was not statistically significant in the fully adjusted models ( $\mathrm{p}$ values ranged from 0.063 to 0.103 ).

Table 4 presents the same three models as in table 3, but with lifetime externalising disorder as the outcome. In these models, being of older age (ORs ranged from 0.41 to 0.43 for age 50-64 compared with age 18-34) and being female (ORs 0.24-0.25) were both significantly protective against externalising disorder, while being married (ORs 1.75-1.96) was significantly positively associated with externalising disorder.

For the neighbourhood-level exposures, higher neighbourhood-level income was not statistically significant in its association (second column), but neighbourhood-level percentage of married individuals (third column) was statistically associated with lower odds of lifetime externalising disorder (OR 0.99, 95\% CI 0.97 to $1.00)$. In other words, each one-point increase in neighbourhood-level percentage of married residents was associated with a $1 \%$ decreased odds of lifetime externalising disorder.

As an alternative interpretation, when the sample was split into tertiles in order to use a categorical variable for percent married (not shown in tables), we found that living in a neighbourhood in the top tertile of the percentage of married residents in each neighbourhood was associated with a $51 \%$ decreased odds of lifetime externalising disorder (OR $0.49,95 \%$ CI 0.27 to 0.89 ), and being in the middle tertile was associated with a $50 \%$ decreased odds of lifetime externalising disorder (OR $0.50,95 \%$ CI 0.28 to 0.89 ), both compared with the bottom tertile.

Finally, the bottom row of table 4 shows that the random effect of an intercept varying at the neighbourhood level was statistically significant in all three models $(\mathrm{p}<0.0001)$, further illustrating that the probability of having history of externalising disorder varied by neighbourhood.

\section{Past-year mental disorder models}

Models for past-year internalising disorders are presented in table 5, with the same independent variables included as in tables 3 and 4 . There were no statistically significant associations among individual-level variables with pastyear internalising disorders in the fully adjusted models, with the exception of being 35 to 49 years old, which was associated with lower odds of past-year internalising disorder in comparison with younger individuals for each model (ORs 0.66-0.69). 
Table 2 Prevalence and means of independent and dependent variables among 4072 urban China residents

\begin{tabular}{|c|c|c|c|c|}
\hline & Unweighted, n & Weighted, \% & Weighted mean & $\begin{array}{l}\text { Weighted design- } \\
\text { based SE }\end{array}$ \\
\hline \multicolumn{5}{|l|}{ Cities } \\
\hline Beijing & 914 & 22.31 & - & $1.38 \%$ \\
\hline Shanghai & 713 & 17.43 & - & $0.90 \%$ \\
\hline Shenzhen & 2445 & 60.26 & - & $1.34 \%$ \\
\hline \multicolumn{5}{|l|}{ Individual-level variables } \\
\hline Age 18-34 & 2046 & 61.96 & & $0.95 \%$ \\
\hline Age $35-49$ & 1353 & 24.11 & - & $0.84 \%$ \\
\hline Age 50-64 & 473 & 8.97 & - & $0.60 \%$ \\
\hline Age $65+$ & 200 & 4.96 & - & $0.50 \%$ \\
\hline Female & 2014 & 49.26 & - & $1.19 \%$ \\
\hline Male & 2058 & 50.74 & & $1.19 \%$ \\
\hline $\begin{array}{l}\text { Ratio of individual income to } \\
\text { city income }\end{array}$ & - & - & 1.63 & 0.05 \\
\hline $\begin{array}{l}\text { In bottom } 50 \% \text { of country-level } \\
\text { education }\end{array}$ & 1302 & 35.70 & - & $1.18 \%$ \\
\hline $\begin{array}{l}\text { In top } 50 \% \text { of country-level } \\
\text { education }\end{array}$ & 2770 & 64.30 & -- & $1.18 \%$ \\
\hline Currently married & 2695 & 59.04 & - & $1.05 \%$ \\
\hline Not currently married & 1377 & 40.96 & - & $1.05 \%$ \\
\hline Migrant to megacity & 2526 & 63.89 & - & $1.18 \%$ \\
\hline Not a migrant to megacity & 1546 & 36.11 & - & $1.18 \%$ \\
\hline Unemployed & 163 & 3.21 & - & $0.45 \%$ \\
\hline Not unemployed & 3909 & 96.79 & - & $0.45 \%$ \\
\hline \multicolumn{5}{|l|}{ Mental disorders } \\
\hline $\begin{array}{l}\text { Any lifetime internalising } \\
\text { disorder }^{*}\end{array}$ & 885 & 9.82 & - & $0.57 \%$ \\
\hline $\begin{array}{l}\text { Any past-year internalising } \\
\text { disorder }\end{array}$ & 559 & 6.31 & - & $0.47 \%$ \\
\hline $\begin{array}{l}\text { Any lifetime externalising } \\
\text { disordert }\end{array}$ & 368 & 4.67 & - & $0.46 \%$ \\
\hline $\begin{array}{l}\text { Any past-year externalising } \\
\text { disorder }\end{array}$ & 230 & 2.66 & - & $0.27 \%$ \\
\hline \multicolumn{5}{|l|}{ Neighbourhood-level variables } \\
\hline $\begin{array}{l}\text { Ratio of neighbourhood income } \\
\text { to city income }\end{array}$ & - & - & 1.05 & 0.01 \\
\hline $\begin{array}{l}\text { Percent married in } \\
\text { neighbourhood }\end{array}$ & - & - & $61.69 \%$ & 0.36 \\
\hline
\end{tabular}

*Internalising disorders include anxiety (post-traumatic stress disorder, panic disorder, specific phobia, social phobia, agoraphobia, adult separation anxiety, generalised anxiety disorder) and mood (major depressive disorder, dysthymic disorder and bipolar/subthreshold bipolar) disorders.

†Externalising disorders include behavioural (intermittent explosive disorder) and substance use (alcohol and drug abuse with or without dependence) disorders.

The second two columns in table 5 show that again, there were no significant associations between neighbourhood-level income and proportion of married residents with odds of internalising disorder. However, the proportion of married residents per neighbourhood neared statistical significance $(\mathrm{p}=0.09)$, and the random effect of the intercept varying at the neighbourhood level was statistically significant in all three models ( $p$ values ranged from 0.021 to 0.007 ).

Table 6 presents the results for past-year externalising disorder as the outcome. In these models, being of older age (ORs $0.05-0.53$ for all age groups compared with 
Table 3 Logistic multilevel, multivariate regression models with lifetime internalising disorder $†$ as the outcome among 4072 urban China residents $\ddagger$

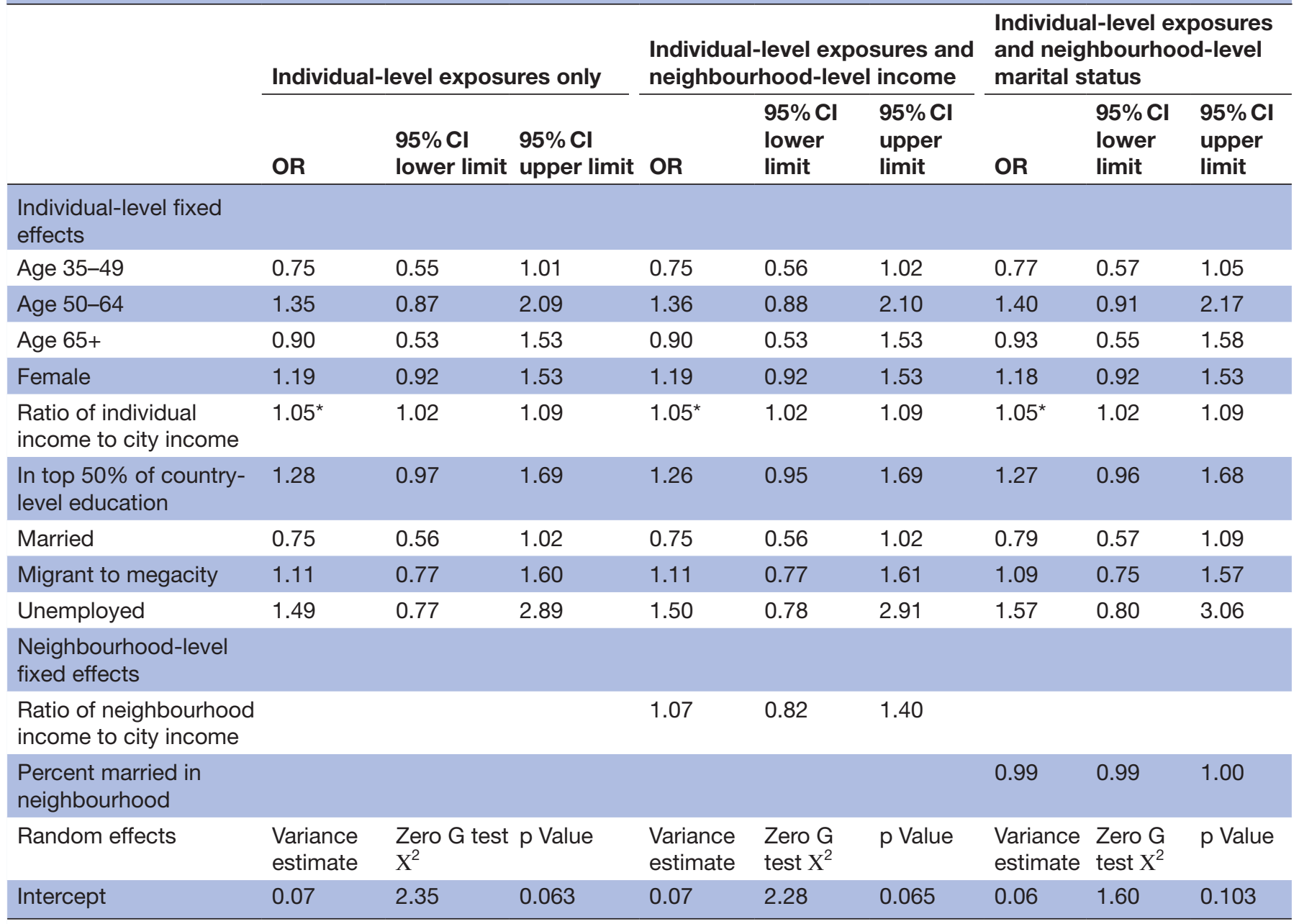

${ }^{*}=\mathrm{p}<0.05$.

†Internalising disorders include anxiety (post-traumatic stress disorder, panic disorder, specific phobia, social phobia, agoraphobia, adult separation anxiety, generalised anxiety disorder) and mood (major depressive disorder, dysthymic disorder and bipolar/subthreshold bipolar) disorders.

¥Models include the above variables as well as fixed effects for city and for having a missing ('do not know' or refused) value on individual unemployment.

being 18-34 years old) and being female (ORs 0.38$0.40)$ were again significantly protective against externalising disorder, and being married (ORs 1.92-2.23) was again significantly positively associated with externalising disorder. Additionally, being unemployed, having a higher educational attainment and having a higher relative individual income were all statistically associated with higher odds of disorder (ORs 5.71-1.04).

For the neighbourhood-level exposures, results were very similar to those with lifetime externalising disorder as the outcome. Higher neighbourhood-level income was not statistically significant (second column), but neighbourhood-level percentage of married individuals (third column) was again statistically associated with lower odds of externalising disorder (OR 0.98, 95\% CI 0.97 to 0.99 ). As an alternative interpretation, when split into tertiles for a categorical exposure variable, living in a neighbourhood in the top tertile of percentage of married residents was associated with a $54 \%$ decreased odds of past-year externalising disorder (OR $0.46,95 \%$ CI 0.24 to 0.87 ).

\section{DISCUSSION}

Using multilevel models with data from three of the largest cities in China, we found that after accounting for individual-level marital status, residence in neighbourhoods with a higher proportion of married individuals was associated with lower odds of both past-year and lifetime externalising, but not internalising, mental disorders. Contrary to our expectations, living in a neighbourhood with a higher median income compared with the city median income was not significantly associated with lower odds either internalising or externalising of disorder.

Despite the differences in samples, this finding is similar to that of Roosa et al who found that neighbourhood disadvantage was not associated as a main effect with 


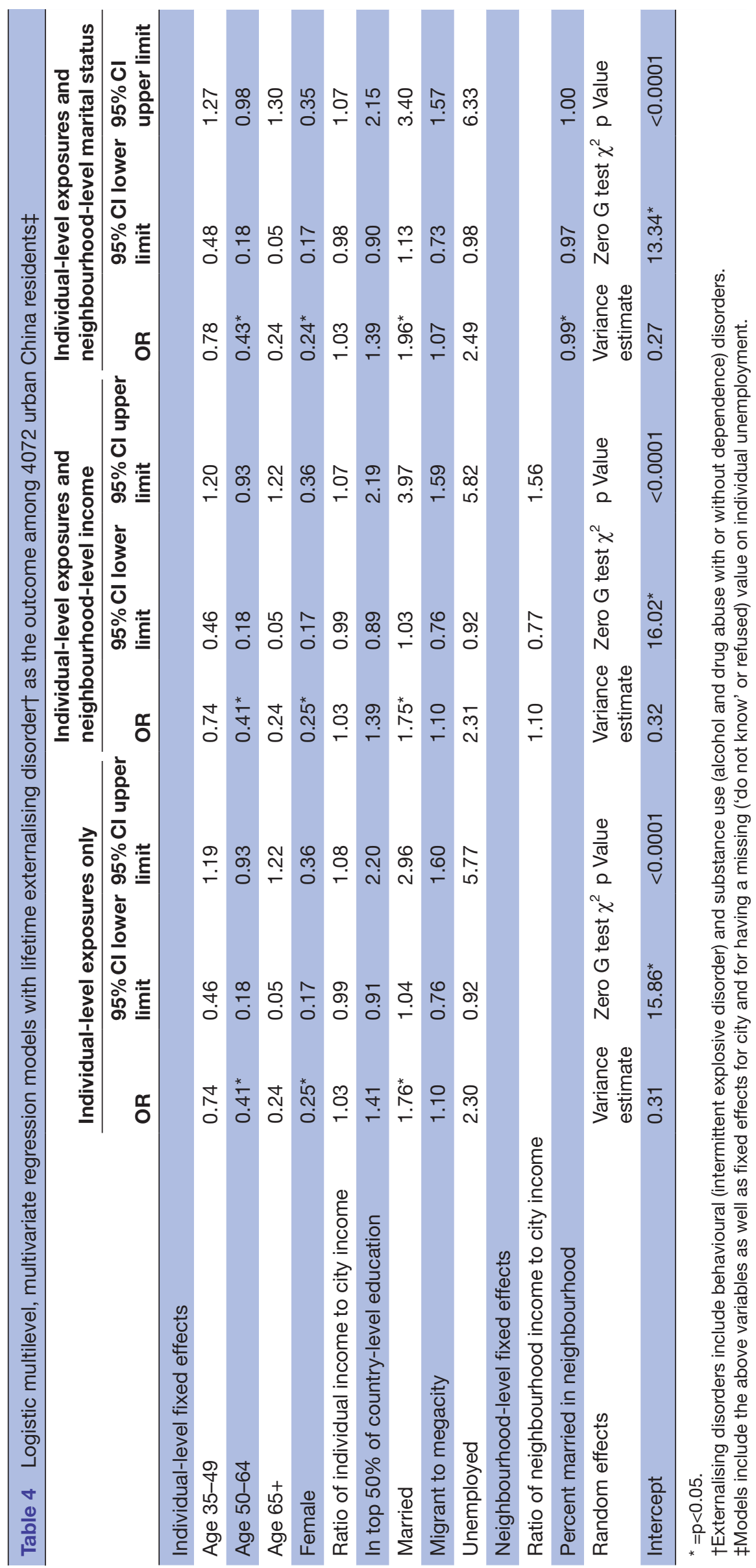


Table 5 Logistic multilevel, regression multivariate models with past-year internalising disorder† as the outcome among 4072 urban China residentsł

\begin{tabular}{|c|c|c|c|c|c|c|c|c|c|}
\hline & \multicolumn{3}{|c|}{ Individual-level exposures only } & \multicolumn{3}{|c|}{$\begin{array}{l}\text { Individual-level exposures and } \\
\text { neighbourhood-level income }\end{array}$} & \multicolumn{3}{|c|}{$\begin{array}{l}\text { Individual-level exposures and } \\
\text { neighbourhood-level marital } \\
\text { status }\end{array}$} \\
\hline & OR & $\begin{array}{l}95 \% \mathrm{CI} \\
\text { lower limit }\end{array}$ & $\begin{array}{l}95 \% \mathrm{Cl} \\
\text { upper limit }\end{array}$ & OR & $\begin{array}{l}95 \% \mathrm{Cl} \\
\text { lower limit }\end{array}$ & $\begin{array}{l}95 \% \mathrm{Cl} \\
\text { upper limit }\end{array}$ & OR & $\begin{array}{l}95 \% \mathrm{Cl} \\
\text { lower limit }\end{array}$ & $\begin{array}{l}95 \% \mathrm{Cl} \\
\text { upper limit }\end{array}$ \\
\hline \multicolumn{10}{|l|}{$\begin{array}{l}\text { Individual-level } \\
\text { fixed effects }\end{array}$} \\
\hline Age 50-64 & 1.27 & 0.73 & 2.19 & 1.27 & 0.73 & 2.19 & 1.34 & 0.77 & 2.32 \\
\hline Age $65+$ & 0.59 & 0.28 & 1.23 & 0.59 & 0.28 & 1.23 & 0.61 & 0.29 & 1.29 \\
\hline Female & 1.17 & 0.83 & 1.65 & 1.17 & 0.83 & 1.65 & 1.16 & 0.82 & 1.63 \\
\hline $\begin{array}{l}\text { Ratio of } \\
\text { individual } \\
\text { income to city } \\
\text { income }\end{array}$ & 1.04 & 0.99 & 1.08 & 1.04 & 1.00 & 1.08 & 1.03 & 0.99 & 1.08 \\
\hline Married & 0.83 & 0.56 & 1.23 & 0.83 & 0.56 & 1.23 & 0.88 & 0.58 & 1.35 \\
\hline $\begin{array}{l}\text { Migrant to } \\
\text { megacity }\end{array}$ & 1.33 & 0.81 & 2.16 & 1.32 & 0.81 & 2.15 & 1.29 & 0.78 & 2.11 \\
\hline Unemployed & 1.44 & 0.87 & 2.37 & 1.43 & 0.87 & 2.36 & 1.54 & 0.92 & 2.59 \\
\hline \multicolumn{10}{|l|}{$\begin{array}{l}\text { Neighbourhood- } \\
\text { level fixed } \\
\text { effects }\end{array}$} \\
\hline $\begin{array}{l}\text { Ratio of } \\
\text { neighbourhood } \\
\text { income to city } \\
\text { income }\end{array}$ & & & & 0.97 & 0.70 & 1.35 & & & \\
\hline Intercept & 0.15 & $5.99^{\star}$ & 0.007 & 0.15 & $5.88^{*}$ & 0.008 & 0.13 & $4.18^{\star}$ & 0.021 \\
\hline
\end{tabular}

${ }^{*}=\mathrm{p}<0.05$.

†Internalising disorders include anxiety (post-traumatic stress disorder, panic disorder, specific phobia, social phobia, agoraphobia, adult separation anxiety, generalised anxiety disorder) and mood (major depressive disorder, dysthymic disorder and bipolar/subthreshold bipolar) disorders.

¥Models include the above variables as well as fixed effects for city and for having a missing ('do not know' or refused) value on individual unemployment.

internalising or externalising symptoms in a sample of Mexican American youth. ${ }^{17}$ However, it is at odds with the finding by Hurd et al that African American adolescents in the USA who lived in areas of higher neighbourhood poverty were more likely to have internalising symptoms as mediated by lower social support. ${ }^{16}$

Two mechanisms have been proposed to explain general associations between lower income and social capital with higher odds of mental disorders: social causation and social selection. ${ }^{334}$ The latter posits that individuals with mental disorders have a predisposition to drift into lower socioeconomic positions, while the former attributes the association to the stress and adversity that comes with having low socioeconomic status. The pathways through which neighbourhood income may affect mental disorders are likely multifactorial and at least partially mediated by individual socioeconomic status, but neighbourhood features and social cohesion are likely to explain some of this association, ${ }^{10}$ as was the case in Hurd et als study. ${ }^{16}$ We were not able to test these hypotheses directly due to the cross-sectional nature of our data, but our results suggest that, in the context of adults living in urban China, neighbourhood income does not in fact appear to be an important driver of mental health outcomes. 
Table 6 Logistic multilevel, multivariate regression models with past-year externalising disorder† as the outcome among 4072 urban China residentsł

\begin{tabular}{|c|c|c|c|c|c|c|c|c|c|}
\hline & \multicolumn{3}{|c|}{$\begin{array}{l}\text { Individual-level exposures } \\
\text { only }\end{array}$} & \multicolumn{3}{|c|}{$\begin{array}{l}\text { Individual-level exposures } \\
\text { and neighbourhood-level } \\
\text { income }\end{array}$} & \multicolumn{3}{|c|}{$\begin{array}{l}\text { Individual-level exposures } \\
\text { and neighbourhood-level } \\
\text { marital status }\end{array}$} \\
\hline & OR & $\begin{array}{l}95 \% \mathrm{Cl} \\
\text { lower } \\
\text { limit }\end{array}$ & $\begin{array}{l}95 \% \mathrm{Cl} \\
\text { upper } \\
\text { limit }\end{array}$ & OR & $\begin{array}{l}95 \% \mathrm{CI} \\
\text { lower } \\
\text { limit }\end{array}$ & $\begin{array}{l}95 \% \mathrm{Cl} \\
\text { upper } \\
\text { limit }\end{array}$ & OR & $\begin{array}{l}95 \% \mathrm{CI} \\
\text { lower } \\
\text { limit }\end{array}$ & $\begin{array}{l}95 \% \mathrm{Cl} \\
\text { upper } \\
\text { limit }\end{array}$ \\
\hline \multicolumn{10}{|l|}{ Individual-level fixed effects } \\
\hline Age 50-64 & $0.17^{\star}$ & 0.07 & 041 & $0.17^{\star}$ & 0.07 & 041 & $0.19^{*}$ & 0.08 & 0.45 \\
\hline Age 65+ & $0.05^{\star}$ & 0.01 & 0.24 & $0.05^{\star}$ & 0.01 & 0.24 & $0.06^{*}$ & 0.01 & 0.27 \\
\hline Female & $0.40^{\star}$ & 0.27 & 0.59 & $0.40^{*}$ & 0.27 & 0.59 & $0.38^{*}$ & 0.26 & 0.57 \\
\hline $\begin{array}{l}\text { Ratio of individual income to city } \\
\text { income }\end{array}$ & $1.05^{\star}$ & 1.00 & 1.09 & $1.04^{*}$ & 1.00 & 1.09 & 1.04 & 0.99 & 1.09 \\
\hline Migrant to megacity & 0.83 & 0.54 & 1.29 & 0.83 & 0.54 & 1.29 & 0.78 & 0.49 & 1.24 \\
\hline Unemployed & $5.01^{*}$ & 2.23 & 11.24 & $5.01^{*}$ & 2.24 & 11.23 & $5.71^{*}$ & 2.50 & 13.05 \\
\hline \multicolumn{10}{|l|}{ Neighbourhood-level fixed effects } \\
\hline $\begin{array}{l}\text { Ratio of neighbourhood income to } \\
\text { city income }\end{array}$ & & & & 1.01 & 0.73 & 1.42 & & & \\
\hline Percent married in neighbourhood & & & & & & & $0.98^{*}$ & 0.97 & 0.99 \\
\hline Random effects & $\begin{array}{l}\text { Variance } \\
\text { estimate }\end{array}$ & $\begin{array}{l}\text { Zero G } \\
\text { test } \chi^{2}\end{array}$ & $\mathrm{p}$ Value & $\begin{array}{l}\text { Variance } \\
\text { estimate }\end{array}$ & $\begin{array}{l}\text { Zero G } \\
\text { test } \chi^{2}\end{array}$ & $\mathrm{p}$ Value & $\begin{array}{l}\text { Variance } \\
\text { estimate }\end{array}$ & $\begin{array}{l}\text { Zero } G \\
\text { test } \chi^{2}\end{array}$ & $\mathrm{p}$ Value \\
\hline Intercept & 0.12 & 1.80 & 0.090 & 0.12 & 1.80 & 0.090 & 0.08 & 1.01 & 0.157 \\
\hline
\end{tabular}

${ }^{*}=\mathrm{p}<0.05$.

†Externalising disorders include behavioural (intermittent explosive disorder) and substance use (alcohol and drug abuse with or without dependence) disorders.

¥Models include the above variables as well as fixed effects for city and for having a missing ('do not know' or refused) value on individual unemployment.

To our knowledge, the proportion of married individuals in a neighbourhood has not been studied in relation to internalising and externalising mental disorders. At the individual level, marital status is very often shown to be associated with mental disorders. ${ }^{35} 36$ The inverse association of neighbourhood-level percentage of married individuals and externalising disorders found in our study suggests a protective community effect of marriage, possibly through its effect on social cohesion. The social control (or social bond) theory primarily used in criminology, which states that traditional social relationships may buffer against externalising behaviour in the form of crime, ${ }^{37}$ may potentially be extended to our results in terms of communities of married families acting as a buffer against their residents developing externalising disorders such as substance abuse.

Additionally, living in a neighbourhood with more married individuals has been associated with higher neighbourhood satisfaction, ${ }^{38}$ and marital status is frequently associated with more political participation and social support. ${ }^{24}$ We were not able to directly analyse neighbourhood social cohesion with our data, but we welcome new studies that test this hypothesis. Another possible explanation is that the neighbourhood marriage distribution is an indicator of other neighbourhood characteristics not measured. For example, previous studies in other contexts have found that areas with higher marriage rates also have more upward mobility, ${ }^{39} 40$ which could plausibly affect local mental health.

Despite our focus on contextual (neighbourhood-level) exposures in this analysis, we also unexpectedly found that being married as an individual and being more highly educated were both associated a with higher odds of externalising disorders, and having higher individual income relative to the city median was associated at the individual level with higher odds of both internalising and externalising disorders. These results were unexpected in contrast to findings in other parts of the world. ${ }^{41}$ However, we propose that in the context of Chinese cities, these characteristics may be indicators of added family or job-related stress resulting from marriage and higher education, especially when controlling for unemployment and for proxies of social cohesion at the neighbourhood level. Being married was also found to 
be an individual risk factor for any disorder in an earlier analysis using WMH data in Beijing and Shanghai only; never having been married was significantly protective against any past-year disorder. ${ }^{14}$ The relationship between marital status and mental disorder also depends on the timing of each condition ${ }^{41}$ as well as severity and type of disorder, ${ }^{14}$ which could be focuses for future papers using urban Chinese data, but were not our focus here.

These results should be interpreted in the context of a few limitations. First, due to the cross-sectional nature of this study, we cannot exclude the possibility of reverse causation that concentrates individuals with externalising mental disorders in neighbourhoods with fewer married individuals, as posited by the social selection theory. ${ }^{33}$ Although this potential for reverse causation cannot be discarded, recent systematic reviews have suggested that there is a consistent association of neighbourhood characteristics with mental health. ${ }^{42}$ Further, Dohrenwend et al found that social causation was a more likely theory than social selection for substance use disorders in men. ${ }^{33}$ Men with substance use disorders are a primary group of those characterised as having externalising disorder in our study, the outcome for which we found the significant relationship with neighbourhood marital status, suggesting that there may in fact be a causal link.

As a second limitation, our study relied on data from lay interviews instead of clinician-administered interviews, which could affect estimates of disease prevalence and predictors. However, our diagnostic assessments have been validated with blinded clinical reappraisal interviews. $^{31}$

Third, our sample is not necessarily representative of today's urban China, given that the data were collected in the early 2000s, or of other large urban areas of China not sampled. Even across the three cities we assessed, there are important differences, most notably the fact that Beijing and Shanghai are two of the oldest large cities in China, while Shenzhen is a migrant industrial city that evolved based on its designation in 1980 as the first PRC Special Economic Zone. In order to control for city-level differences in costs of living, we measured individual income as the ratio of individual income to median city-level income, but other differences may remain. In our sample, Beijing had the highest prevalence of disorder, followed by Shenzhen and then Shanghai, and we included city as a control variable in our models.

Furthermore, socioeconomic characteristics likely have differential effects on the health of migrants depending on the culture and area of origin, ${ }^{43}$ which could modify our results. Some new neighbourhoods in China, especially in Shenzhen, are composed of groups of migrants of similar ages, originating from the same areas, and living in small areas such as dormitories ${ }^{44}$ where high social cohesion could influence mental health outcomes. Our analysis of migration was limited by the absence of detailed data on the respondents' area of origin and current housing. However, we did statistically control for whether the respondent grew up mostly in a large city. Future studies should investigate the associations of these factors with mental disorders in a sample with more detailed information on migration status.

Despite these limitations, our study is the first to investigate the associations of neighbourhood characteristics with mental disorders in large urban areas of China, providing data that may be consistent with previous concerns about the mental health effects of community disruption created by rapid urbanisation. $^{45} 46$

Mental disorders are a growing public health problem in China. The government has recently taken steps to address the problem by creating hundreds of new psychiatric hospitals and integrating its resources with existing community health systems. ${ }^{45}$ A few recent sociodemographic changes such as the increasing globalisation of its economy and the end of the one-child policy may also significantly improve neighbourhood characteristics. However, more progress will likely be needed to develop broad social measures for enhancing social cohesion, participation, and support to help manage the consequences of decades of underdiagnosed mental disorders.

The large and rapid urbanisation process that China went through during the past few decades has been recently replicated, on a much smaller scale, in other countries. While there are important early benefits of urbanisation, the frequently chaotic expansion of urban areas can be associated with community disruption and the worsening of health outcomes. A growing number of low-income individuals now live in large urban areas that do not provide the social support and stability found in smaller communities. Understanding the effects of neighbourhood characteristics on mental disorders in fast growing regions of the world can help to promote better neighbourhood environments and control the burden of mental disorders in emerging countries.

One direction for future research would be to further investigate the role of migration. A high proportion of individuals in our sample and in urban China as a whole were born in rural areas. Migrating from rural to urban areas is not only prevalent in China, but also likely to be associated with both marital status and income in addition to mental health. ${ }^{13}$ Investigators should continue to study the relationships among important neighbourhood-level indicators of health, including a more specific measure of migration status at both an individual and neighbourhood level. Finally, another potentially fruitful direction for future research could be to investigate how the distribution of mental disorders at the neighbourhood level might act as a potential predictor for individual disorder outcomes, preferably in a longitudinal setting. 
Author affiliations

${ }^{1}$ Department of Epidemiology, School of Public Health of the University of Sao Paulo, Sao Paulo, Brazil

${ }^{2}$ Department of Epidemiology, Boston University School of Public Health, Boston, Massachusetts, USA

${ }^{3}$ Department of Epidemiology, Columbia University Mailman School of Public Health, New York, USA

${ }^{4}$ Institute of Mental Health, Peking University Sixth Hospital, Beijing, China

${ }^{5}$ Department of Psychiatric Epidemiology and Psychiatry, Shanghai Mental Health

Center, Shanghai Jiao Tong University School of Medicine, Shanghai, China

${ }^{6}$ Department of Psychiatry, Chinese University of Hong Kong, Hong Kong, China

${ }^{7}$ Shenzhen Institute of Mental Health and Shenzhen Kangning Hospital, Shenzhen, China

${ }^{8}$ Department of Health Care Policy, Harvard Medical School, Boston, Massachusetts, USA

Acknowledgements We thank the staff of the WMH Data Collection and Data Analysis Coordination Centres for assistance with instrumentation, fieldwork, and consultation on data analysis. None of the funders had any role in the design, analysis, interpretation of results, or preparation of this paper. A complete list of all within-country and cross-national WMH publications can be found at the http:// www.hcp.med.harvard.edu/wmh/

Contributors ADPCF designed initial statistical analyses; conducted the literature review; performed preliminary analyses; wrote the introduction and discussion sections; and critically edited all versions of the manuscript. LS aided in the literature review and writing of introduction and discussion sections; wrote the methods and results sections; designed the revised analyses; created tables; and critically edited all versions of the manuscript. SSM helped to design statistical analyses; participated in interpretation of results; and critically edited all versions of the manuscript. SY performed statistical analyses; created tables; and critically edited all versions of the manuscript. YH carried out the Beijing data acquisition; participated in interpretation of results; and critically edited all versions of the manuscript. YH carried out the Shanghai data acquisition; participated in interpretation of results; and critically edited all versions of the manuscript. SL co-ordinated data acquisition and critically edited all versions of the manuscript. $\mathrm{CH}$ carried out the Shenzhen data acquisition and critically edited all versions of the manuscript. AZ designed data analyses; provided statistical support; participated in interpretation of results; and critically edited all versions of the manuscript. RCK conceptualised and co-ordinated the study; participated in interpretation of results; and critically edited all versions of the manuscript. SG conceptualised the analyses; formulated hypotheses; led the analytic team; and critically edited all versions of the manuscript. All authors approved the final version and stand behind all aspects of the work.

Funding This study was carried out in conjunction with the World Health Organization World Mental Health (WMH) Survey Initiative which is supported by the National Institute of Mental Health (NIMH; R01 MH070884), the John D. and Catherine T. MacArthur Foundation, the Pfizer Foundation, the US Public Health Service (R13-MH066849, R01- MH069864 and R01DA016558), the Fogarty International Center (FIRCA R03-TW006481), the Pan American Health Organization, Eli Lilly and Company, Ortho-McNeil Pharmaceutical, GlaxoSmithKline and Bristol-Myers Squibb. The Chinese World Mental Health Survey Initiative is supported by the Pfizer Foundation. The Shenzhen Mental Health Survey is supported by the Shenzhen Bureau of Health and the Shenzhen Bureau of Science, Technology, and Information. The analyses were partially supported by the Fundação de Amparo à Pesquisa do Estado de São Paulo(FAPESP, grant number: 14/05363-7).

Competing interests In the past three years, Kessler received support for his epidemiological studies from Sanofi Aventis; was a consultant for Johnson \& Johnson Wellness and Prevention, Shire, Takeda; and served on an advisory board for the Johnson \& Johnson Services, inc Lake Nona Life Project. Kessler is a coowner of DataStat, inc, a market research firm that carries out health care research. Other authors have no financial or personal conflicts of interest to disclose.

Ethics approval Ethics committees of Peking University and Shenzhen Kanging Hospital

Provenance and peer review Not commissioned; externally peer reviewed.

Open Access This is an Open Access article distributed in accordance with the Creative Commons Attribution Non Commercial (CC BY-NC 4.0) license, which permits others to distribute, remix, adapt, build upon this work non-commercially, and license their derivative works on different terms, provided the original work is properly cited and the use is non-commercial. See: http://creativecommons.org/ licenses/by-nc/4.0/

(C) Article author(s) (or their employer(s) unless otherwise stated in the text of the article) 2017. All rights reserved. No commercial use is permitted unless otherwise expressly granted.

\section{REFERENCES}

1. National Bureau of Statistics of China.2012: http://www.stats.gov.cn/ english/statisticaldata/AnnualData/

2. Gong $\mathrm{P}$, Liang $\mathrm{S}$, Carlton EJ, et al. Urbanisation and health in China. Lancet 2012;379:843-52.

3. Collins PY, Patel V, Joestl SS, et al. Grand challenges in global mental health: a consortium of researchers, advocates and clinicians announces here research priorities for improving the lives of people with mental illness around the world, and calls for urgent action and investment. Nature 2011;475:27-30.

4. Yang G, Wang Y, Zeng Y, et al. Rapid health transition in China, 19902010: findings from the Global Burden of Disease Study 2010. Lancet 2013;381:1987-2015.

5. Yu W-hsin, Chiu C-T. Growing pains: changes in psychological wellbeing in urban china. Soc Indic Res 2016;129:1349-82.

6. Phillips MR, Zhang J, Shi Q, et al. Prevalence, treatment, and associated disability of mental disorders in four provinces in China during 2001-05: an epidemiological survey. Lancet 2009;373:2041-53.

7. WHO. Closing the gap in a generation: Health equity through action on the social determinants of health. Switzerland: Commision On Social Determinants Of Health, 2008.

8. WHO. Discussion Paper Series on Social Determinants of Health. Switzerland, 2010. (Epub ahead of print $26 \mathrm{Dec}$ ).

9. Piketty T. Capital in the Twenty-First Century. Cambridge: Belknap Press, 2014.

10. Mair C, Diez Roux AV, Galea S. Are neighbourhood characteristics associated with depressive symptoms? A review of evidence. $J$ Epidemiol Community Health 2008;62:940-6.

11. Muntaner C, Eaton WW, Miech R, et al. Socioeconomic position and major mental disorders. Epidemiol Rev 2004;26:53-62.

12. Nieuwenhuis J, van Ham M, Yu R, et al. Being poorer than the rest of the neighborhood: relative deprivation and problem behavior of youth. J Youth Adolesc 2017:1891-904.

13. Wen M, Fan J, Jin L, et al. Neighborhood effects on health among migrants and natives in Shanghai, China. Health Place 2010;16:452-60.

14. Shen $Y C$, Zhang MY, Huang $Y Q$, et al. Twelve-month prevalence, severity, and unmet need for treatment of mental disorders in metropolitan China. Psychol Med 2006;36:257-67.

15. Krueger RF, McGue M, lacono WG. The higher-order structure of common DSM mental disorders: internalization, externalization, and their connections to personality. Pers Individ Dif 2001;30:1245-59.

16. Hurd NM, Stoddard SA, Zimmerman MA. Neighborhoods, social support, and african american adolescents' mental health outcomes: a multilevel path analysis. Child Dev 2013;84:858-74.

17. Roosa MW, Burrell GL, Nair RL, et al. Neighborhood disadvantage, stressful life events, and adjustment among Mexican American early adolescents. J Early Adolesc 2010;30:567-92.

18. Signorello LB, Cohen SS, Williams DR, et al. Socioeconomic status, race, and mortality: a prospective cohort study. Am J Public Health 2014;104:e98-e107.

19. Pickett KE, Pearl M. Multilevel analyses of neighbourhood socioeconomic context and health outcomes: a critical review. $J$ Epidemiol Community Health 2001:55:111-22.

20. Braveman P, Egerter S, Williams DR. The social determinants of health: coming of age. Annu Rev Public Health 2011;32:381-98.

21. Astell-Burt T, Mitchell R, Hartig T. The association between green space and mental health varies across the lifecourse. A longitudinal study. J Epidemiol Community Health 2014;68:578-83.

22. Albor C, Uphoff EP, Stafford M, et al. The effects of socioeconomic incongruity in the neighbourhood on social support, self-esteem and mental health in England. Soc Sci Med2014;111:1-9.

23. Rios R, Aiken LS, Zautra AJ. Neighborhood contexts and the mediating role of neighborhood social cohesion on health and psychological distress among Hispanic and non-Hispanic residents. Ann Behav Med 2012;43:50-61.

24. Xu Q, Perkins DD, Chow JC. Sense of community, neighboring, and social capital as predictors of local political participation in China. Am J Community Psychol 2010;45:259-71.

25. Hu C. The impact of migration and mental disorders on suicidal behaviors: an epidemiological survey among general population in 
Shenzhen, China. Submitted for the degree of Doctor of Philosophy in Social Work \& Social Administration at the University of Hong Kong. China: BiblioBazaar, 2008.

26. Heeringa SG, Wells EJ, Hubbard F, et al. Sample designs and sampling procedures. In: Kessler RC, Üstün TB, eds. The WHO World Mental Health Surveys: Global perspectives on the epidemiology of mental disorders. New York: Cambridge University Press, 2008:14-32.

27. Harkness J, Pennell BE, Villar A, et al. Translation procedures and translation assessment in the World Mental Health Survey Initiative. In: Kessler RC, Üstün TB, eds. The WHO World Mental Health Surveys: Global perspectives on the epidemiology of mental disorders. New York: Cambridge University Press, 2008:91-113.

28. Kessler RC, Ustün TB. The World Mental Health (WMH) survey initiative version of the World Health Organization (WHO) composite international diagnostic interview (CIDI). Int J Methods Psychiatr Res 2004;13:93-121.

29. Diagnostic and Statistical Manual of Mental Disorders: DSM-IV-TR 4th edn. Washington: American Psychiatric Association, 2000.

30. First MB, Spitzer RL, Gibbon M, et al. Structured Clinical Interview for DSM-IV-TR Axis I Disorders, Research Version, Patient Edition (SCID-I/P). New York: Biometrics Research, New York State Psychiatric Institute, 2002

31. Haro JM, Arbabzadeh-Bouchez S, Brugha TS, et al. Concordance of the composite international diagnostic interview version 3.0 (CIDI 3.0) with standardized clinical assessments in the WHO World Mental Health surveys. Int J Methods Psychiatr Res 2006;15:167-80.

32. Ene M, Leighton EA, Blue GL, et al. Paper 3430-2015: Multilevel Models for Categorical Data Using SAS $\otimes P R O C$ GLIMMIX: The Basics. 2015 https://support.sas.com/resources/papers/ proceedings 15/3430-2015.pdf

33. Dohrenwend BP, Levav I, Shrout PE, et al. Socioeconomic status and psychiatric disorders: the causation-selection issue. Science 1992;255:946-52.

34. Sareen J, Afifi TO, McMillan KA, et al. Relationship between household income and mental disorders: findings from a populationbased longitudinal study. Arch Gen Psychiatry 2011;68:419-27.
35. Kessler RC, Berglund P, Demler O, et al. Lifetime prevalence and age-of-onset distributions of DSM-IV disorders in the National Comorbidity Survey Replication. Arch Gen Psychiatry 2005;62:593-602.

36. Ye M, Chen Y. The influence of domestic living arrangement and neighborhood identity on mental health among urban Chinese elders. Aging Ment Health 2014;18:40-50.

37. Hirschi T. Causes of Delinquency. Berkeley: University of California Press, 1969.

38. Hipp J. What is the "neighbourhood" in neighbourhood satisfaction? Comparing the effects of structural characteristics measured at the micro-neighbourhood and tract levels. Urban Stud 2010;47:2517-36.

39. Chetty R, Hendren N. The impacts of neighborhoods on intergenerational mobility: Childhood exposure effects and countylevel estimates. The National Bureau of Economics Research. 2015.

40. Wilcox WB, Price J, Lerman RI, et al. Prosperous states: do healthy families affect the wealth of states? The American Enterprise Institute; Institute for Family Studies. 2015.

41. Breslau J, Miller E, Jin R, et al. Mental disorders, marriage, and divorce. In: Alonso J, Chatterji S, He Y, eds. The Burden of Mental Disorders: Global Perspectives from the WHO World Mental Health Surveys. Cambridge: Cambridge University Press, 2013.

42. Ribeiro WS, Bauer A, Andrade MCR, et al. Income inequality and mental illness-related morbidity and resilience: a systematic review and meta-analysis. Lancet Psychiatry 2017;4:554-62.

43. Sardadvar S. How migrant status affects health beyond socioeconomic status: evidence from Austria. Int Migr Rev 2015:49:843-77.

44. Wang YP, Wang Y, Wu J. Housing migrant workers in rapidly urbanizing regions: a study of the Chinese model in Shenzhen. Hous Stud 2010;25:83-100.

45. Xiang YT, Yu X, Sartorius N, et al. Mental health in China: challenges and progress. Lancet 2012;380:1715-6.

46. Yan M. Experiences of Poverty and Shame in Urban China. In: Chase E, Bantebya-Kyomuhendo G, eds. Poverty and Shame: Global Experiences. Oxford: Oxford University Press, 2014. 